\title{
Yield Modelling of Oil-Bearing Rose Depending on Irrigation Regime
}

\author{
Nedko Nedkov ${ }^{1}$, Rangel Zaykov ${ }^{2}$, Alexander Matev ${ }^{2}$, Antoniya Ovcharova ${ }^{2}$, \\ Hristofor Kirchev ${ }^{* 2}$ \\ ${ }^{1}$ Institute for roses and aromatic plants - Kazanlak 6100 \\ ${ }^{2}$ Agricultural University - Plovdiv 4000
}

Accepted June, 2017

\begin{abstract}
The aim of this study is to be investigated "Yield - irrigation depth" relationship for white breading rose in the conditions of Kazanlak's Valley (south part of Bulgaria). The field experiment was carried out during $2009-2011$ period with following variants: 1) without irrigation; 2) irrigation with $50 \%$ of the irrigation depth; 3) irrigation with $75 \%$ of the irrigation depth; 4 ) full irrigation (100\% of calculated irrigation depth). This relationship is established in two directions - for blossom and for oil, using the degree equation: $Y i=1-(1-Y d) x(1-x i) n$, (where $Y i$ is the yield by irrigation depth $x i, Y d$ - yield without irrigation, $x i$ - relative irrigation depth and $n$ - exponent). The results show that used equation presents very accurately the change of the yield depending on level of the irrigation depth. The value of " $n$ " is from 1.0 to 1.2 and $R>0.94$. There is linear relationship (by R2>0.8), which allows predicting the yield of oil by data for yield of blossom.
\end{abstract}

Key words: Rosa alba L., irrigation, yield.

\section{Introduction}

The relationship between yield and irrigation dept is being studied for all major agricultural crops, such as its parameters would serve for farmers to optimize the components of the irrigation regime and maximize the economic impact of irrigation. Mathematically this relationship is represented by the equation, the parameters of which are established on the basis of existing experimental data. Applying particular equation can be calculated the relative yield, corresponding to each set of relative irrigation dept.

In the specialized scientific literature there are different proposals for interpretation of this relationship, some authors believe that it is linear [1-2], and according to others, it is subject to the equation of the second degree [3-6]. This means that the yield is not proportionally increased to the

\footnotetext{
* Corresponding author: Hristofor Kirchev,
} hristofor kirchev@abv.bg

(cc) BY-NC-ND $\odot 2017$ Nedko Nedkov et al., published by De Gruyter Open. This work was licensed under the Creative Commons Attribution-NonCommercialNoDerivs 3.0 License increase of the magnitude of the amount of irrigation. Senchukov, G.A. [7] found out the parameters of the relationship in a number of crops, as in each case the relationship is expressed graphically by a parabola. According to the authors yields increase with the rate of irrigation variation in a certain interval, then at the next increase they do not change or begin to decline.

The aim of the study is to establish the parameters of the relationship "Yield - irrigation depth" for white bearing rose (Rosa alba L.) in conditions of Kazanlak's Valley [8].

\section{Material and Methods}

For the purpose of the study of irrigation regime of white bearing rose (Rosa alba L.) have been used data from three-year field experiment (2009 2011) in the Institute of Rose and essential oil crops, town of Kazanlak. The soil type at the site of experience is characterized as leached cinnamonic forest, alluvial - diluvial, light to medium sandy loam. 
The experience was conducted by the method of long plots in four replications in a scheme of planting $3.0 \mathrm{~m} \times 0,7 \mathrm{~m}$ (5950 plants per $1 \mathrm{ha}$ ). The variants including in this study are the following: 1) non - irrigated; 2) irrigation with $50 \%$ reduction of the irrigation depth, calculated at the optimal variant $(50 \% \mathrm{~m}) ; 3)$ irrigation with $25 \%$ reduction of the irrigation depth, calculated at the optimal variant $(75 \% \mathrm{~m})$ and 4$)$ optimum irrigation (100\% m).

The irrigation rates were done by drip system as the soil moisture contents in the optimal variant(variant 4 ) was maintained of 80 to $85 \%$ of field capacity in the layer of $0-0,60 \mathrm{~m}$. Dynamics of soil moisture in the layer $0-1.00 \mathrm{~m}$ was monitored periodically (once a week) by a weighting method. The parameters of "Yield irrigation depth" relationship has been established by the method of least squares by exponent formula of [9-10], which is as follows:

$\mathrm{Yi}=1-(1-\mathrm{Yd}) \times(1-\mathrm{xi}) \mathrm{n}$

Where: $Y i$ is the yield by irrigation depth $x i$;
Yd - yield without irrigation;

$x i$ - relative irrigation depth;

$\mathrm{n}$ - exponent

The study was conducted in two directions - yield of blossom and yield of oil, and the data processing was done using a specialized computer program "YIELD" [10].

\section{Results and Discussions}

Output data for determining the "Yield - irrigation depth" relationship average for tree-year experiment are presented in Table 1.

- Relationship between yield of blossom and irrigation depth by white bearing rose.

The data in columns 3 and 5 of Table 1 are used to be established this relationship.

The obtained average results during the years, and total for experimental period are presented graphically in Figure 1. In Table 2 are listed the parameters of the relationship with their deviations of the calculated magnitudes to the experimental yields.

Table 1

Output data for determining the parameters of "Yield - irrigation depth" relationship by white bearing rose (Rosa Alba L.)

\begin{tabular}{|c|c|c|c|c|c|c|}
\hline \multirow[t]{2}{*}{ Year } & \multirow[t]{2}{*}{ Variant } & \multirow[t]{2}{*}{$x_{i}=M_{i} / M_{0}$} & \multicolumn{2}{|c|}{ Yield of blossom } & \multicolumn{2}{|c|}{ Yield of oil } \\
\hline & & & kg/ha & $\mathrm{Y}_{\mathrm{i}} / \mathrm{Y}_{0}$ & kg/ha & $\mathrm{Y} / \mathrm{Y}_{0}$ \\
\hline 1 & 2 & 3 & 4 & 5 & 6 & 7 \\
\hline \multirow[t]{4}{*}{2009} & 1 & 0.00 & 50.3 & 0.653 & 8.30 & 0.359 \\
\hline & 2 & 0.50 & 63.4 & 0.823 & 15.00 & 0.649 \\
\hline & 3 & 0.75 & 67.9 & 0.882 & 19.80 & 0.857 \\
\hline & 4 & 1.00 & 77.0 & 1.000 & 23.10 & 1.000 \\
\hline \multirow[t]{4}{*}{2010} & 1 & 0.00 & 478 & 0.823 & 8.33 & 0.570 \\
\hline & 2 & 0.50 & 52.4 & 0.902 & 10.53 & 0.654 \\
\hline & 3 & 0.75 & 53.7 & 0.924 & 14.40 & 0.874 \\
\hline & 4 & 1.00 & 58.1 & 1.000 & 15.33 & 1.000 \\
\hline \multirow[t]{4}{*}{2011} & 1 & 0.00 & 20.7 & 0.527 & 4.09 & 0.354 \\
\hline & 2 & 0.50 & 30.8 & 0.784 & 7.62 & 0.660 \\
\hline & 3 & 0.75 & 34.6 & 0.880 & 10.21 & 0.885 \\
\hline & 4 & 1.00 & 39.3 & 1.000 & 11.54 & 1.000 \\
\hline \multirow[t]{4}{*}{ Average } & 1 & 0.00 & 39.6 & 0.682 & 6.91 & 0.415 \\
\hline & 2 & 0.50 & 48.9 & 0.842 & 11.05 & 0.663 \\
\hline & 3 & 0.75 & 52.1 & 0.897 & 14.8 & 0.888 \\
\hline & 4 & 1.00 & 58.1 & 1.000 & 16.66 & 1.000 \\
\hline
\end{tabular}

$\mathrm{M}_{0}$ - Maximum irrigation depth ( $\left.\mathrm{mm}\right) ; \mathrm{Y}_{0}-$ Maximum yield $(\mathrm{kg} / \mathrm{ha})$

The relationship for the first year's experience is linear, but for the second and third is exponential, respectively with exponent $n=1.1$ and $n=1.2$. Thus graphically are expressed by slightly convex parabolas. The character of the relationship is predetermined by well expressed lower efficacy of the reduced irrigation depth in the three years experiment. The used formula demonstrates a very high accuracy, as the correlation coefficient is $\mathrm{R}>0.97$. The approximation for all experimental points is at $R=0,995$ and $n=1.1$ simultaneously. In Figure 2 are presented the experimental data and calculated according to the formula data for yields in parallel. Figure 3 shows their relationship with coefficient $R=0.995$. According to the graphs of both figures the calculated yield of blossom was slightly higher than that experimentally established as a difference does not exceed $4 \%$. 
By years and average

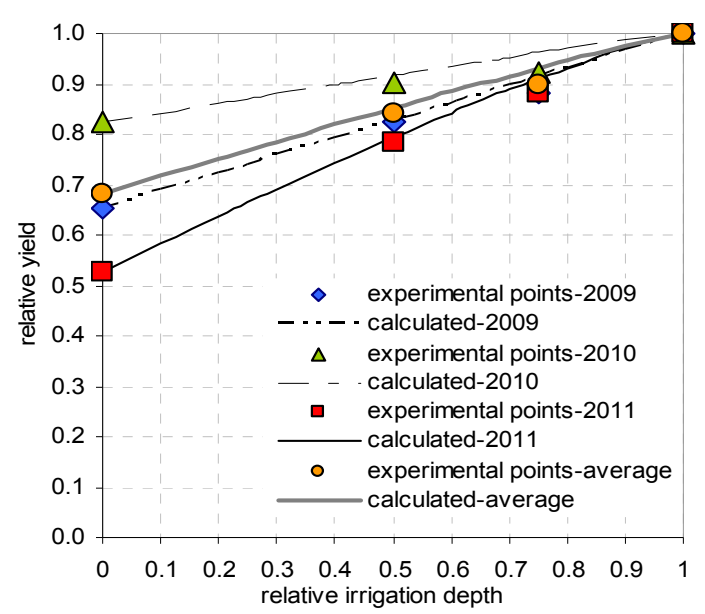

Total (all experimental data)

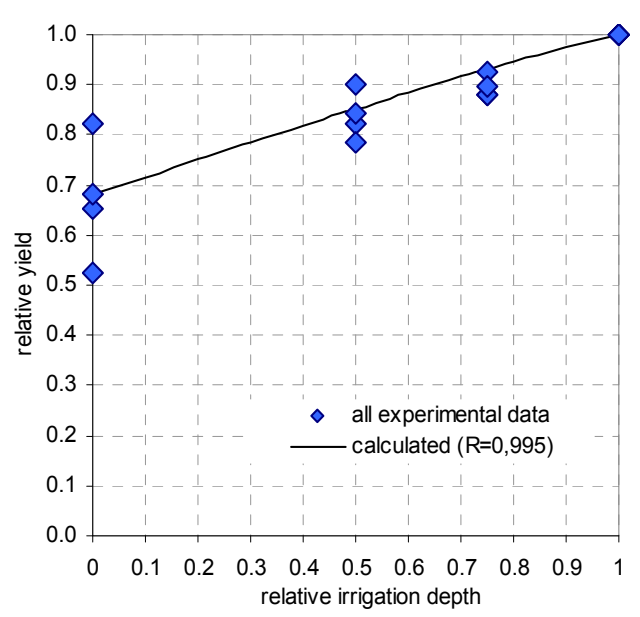

Fig.1. Relationship between yield of blossom and irrigation depth by white bearing rose

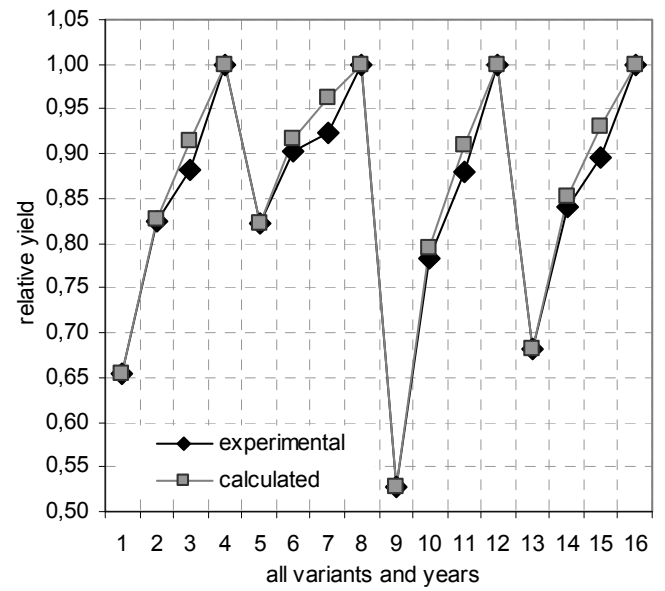

Fig. 2. Experimental and calculated additional yield for all variants and years

- Relationship between yield of oil and irrigation water by white bearing rose.

The data in columns 3 and 7 of Table 1 are used to be established this relationship. The average and total results during the experimental years are graphically presented in Figure 4. The parameters of the relationship with the deviations of the calculated values to experimental yields are also plotted in Table 2.

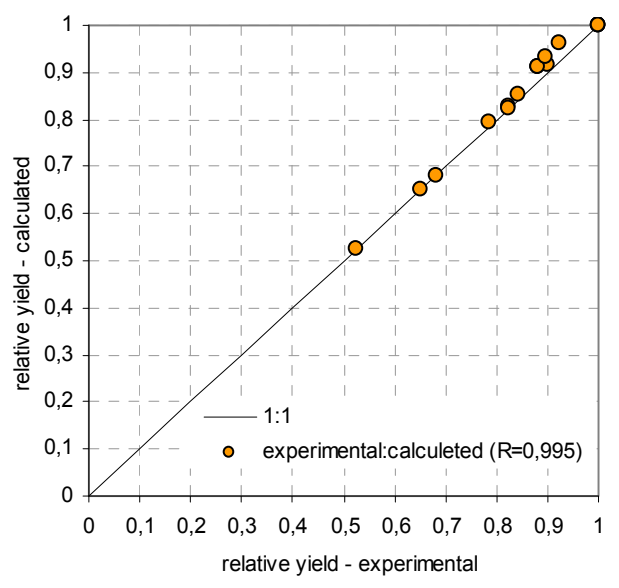

Fig. 3. Relationship "experimental-calculated yield"

Relationship between yield of oil and irrigation depth for the first year's experience is linear. During the second and third years the relationship is expressed graphically by slightly convex parabolas, respectively with exponent $n=1.1$ and $\mathrm{n}=1.2$. Here, the used formula for experimental data is with very high accuracy ( $R>0.94)$. The correlation coefficient of all experimental points is $\mathrm{R}=0,985$ with exponent $\mathrm{n}=1.1$. 
Table2.

The parameters of the "Yield - irrigation depth" and deviations of the calculated values to the experimental yields by white bearing rose (Rosa alba L.)

\begin{tabular}{|c|c|c|c|c|c|c|c|}
\hline \multirow[t]{3}{*}{ Years } & \multirow{3}{*}{ Variant } & \multicolumn{3}{|c|}{$\begin{array}{l}\text { Yield of blossom } \\
\end{array}$} & \multicolumn{3}{|c|}{ Yield of oil } \\
\hline & & \multirow{2}{*}{ Parameters } & \multicolumn{2}{|c|}{ Deviation \pm} & \multirow{2}{*}{ Parameters } & \multicolumn{2}{|c|}{ Deviation \pm} \\
\hline & & & kg/ha & $\%$ & & kg/ha & $\%$ \\
\hline \multirow[t]{4}{*}{2009} & 0.00 & \multirow{4}{*}{$\begin{array}{l}R=0.995 \\
n=1.0 \\
Y_{d}=0.653\end{array}$} & 0.0 & 0.0 & \multirow{4}{*}{$\begin{array}{l}R=0.998 \\
n=1.0 \\
Y_{d}=0.359\end{array}$} & 0.0 & 0.0 \\
\hline & 0.50 & & +0.25 & +0.4 & & +0.70 & +4.7 \\
\hline & 0.75 & & +2.42 & +3.6 & & -0.40 & -2.0 \\
\hline & 1.00 & & 0.0 & 0.0 & & 0.0 & 0.0 \\
\hline \multirow[t]{4}{*}{2010} & 0.00 & \multirow{4}{*}{$\begin{array}{l}R=0.973 \\
n=1.1 \\
Y_{d}=0.823\end{array}$} & 0.0 & 0.0 & \multirow{4}{*}{$\begin{array}{l}R=0.948 \\
n=1.1 \\
Y_{d}=0.544\end{array}$} & 0.17 & 2.0 \\
\hline & 0.50 & & +0.89 & +1.7 & & +1.38 & +13.1 \\
\hline & 0.75 & & +2.16 & +4.0 & & -0.78 & -5.4 \\
\hline & 1.00 & & 0.0 & 0.0 & & 0.0 & 0.0 \\
\hline \multirow[t]{4}{*}{2011} & 0.00 & \multirow{4}{*}{$\begin{array}{l}R=0.998 \\
n=1.2 \\
Y_{d}=0.527\end{array}$} & 0.0 & 0.0 & \multirow{4}{*}{$\begin{array}{l}R=0.994 \\
n=1.2 \\
Y_{d}=0.354\end{array}$} & 0.0 & 0.0 \\
\hline & 0.50 & & +0.40 & +1.3 & & +0.68 & +8.9 \\
\hline & 0.75 & & +1.18 & +3.4 & & -0.08 & -0.8 \\
\hline & 1.00 & & 0.0 & 0.0 & & 0.0 & 0.0 \\
\hline \multirow[t]{4}{*}{ Average } & 0.00 & \multirow{4}{*}{$\begin{array}{l}R=0.993 \\
n=1.1 \\
Y_{d}=0.682\end{array}$} & 0.0 & 0.0 & \multirow{4}{*}{$\begin{array}{l}R=0.991 \\
n=1.1 \\
Y_{d}=0.415\end{array}$} & 0.0 & 0.0 \\
\hline & 0.50 & & +0.57 & +1.2 & & +1.06 & +9.6 \\
\hline & 0.75 & & +1.97 & +3.8 & & -0.26 & -1.8 \\
\hline & 1.00 & & 0.0 & 0.0 & & 0.0 & 0.0 \\
\hline
\end{tabular}

By years and average

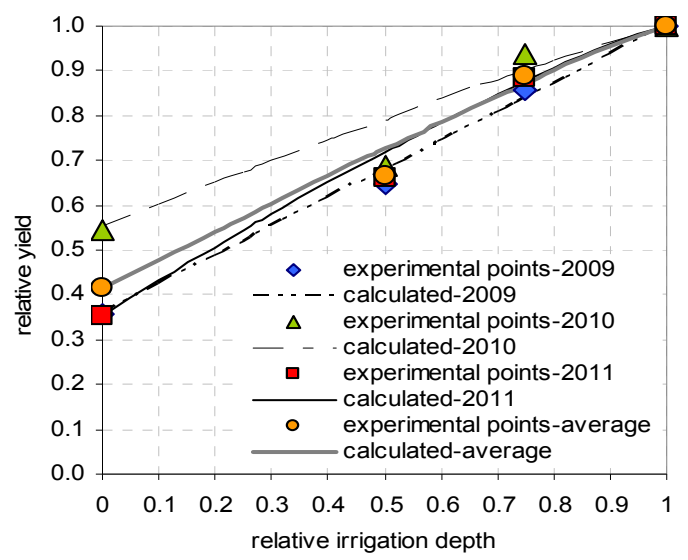

Total (all experimental data)

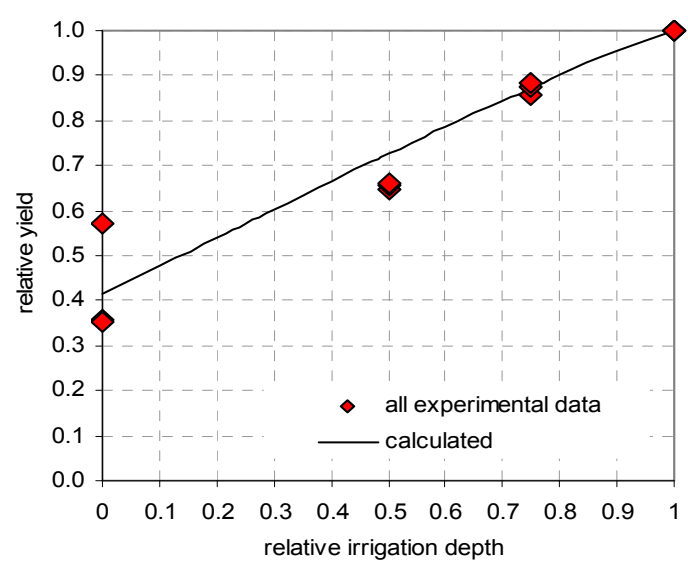

Fig. 4. Relationship between yield of oil and irrigation depth

In Figure 5 are presented together the experimental and calculated by formula yield of oil, and in Figure 6 the relationship experimented -calculated yield of oil with coefficient of correlation $\mathrm{R}=0.985$. The variation here is more considerable (from -5.4 to $+13.1 \%$ ), compared with the yield of blossom. These differences are mainly due to the influence of the irrigation regime on the content of essential oils in the blossom of white bearing rose.

Using data of yield of blossom and oil is determined the relationship between them, which is linear with R2 $>0.8$. In Figure 8 are compared respectively calculated and experimental values of yield, and derived two correlations. They are graphically plotted, where it is obviously that they are practically coincided and the parameters of the two linear equations are almost the same. This confirms the high accuracy of the established relationship between the yield of oil and irrigation depth. So using one of the two equations (Fig. 7.) it could be in advance calculated the yield of oil through data of yield of blossom. 


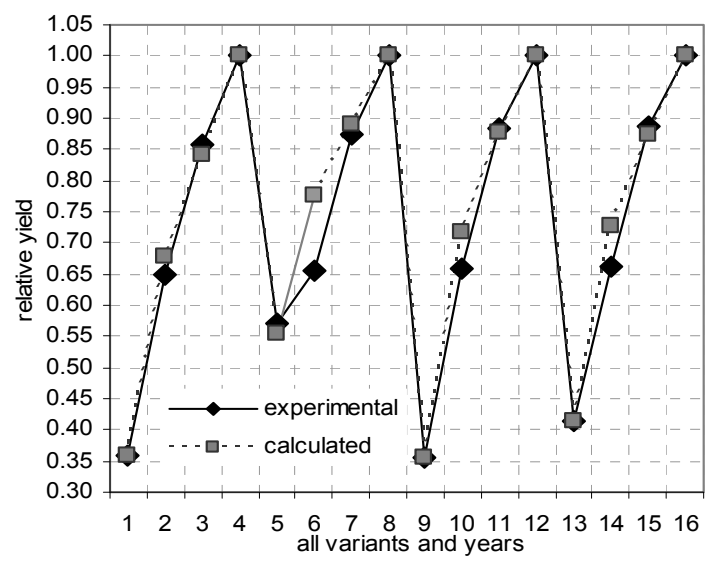

Fig. 5. Experimental and calculated additional yield for all variants and years

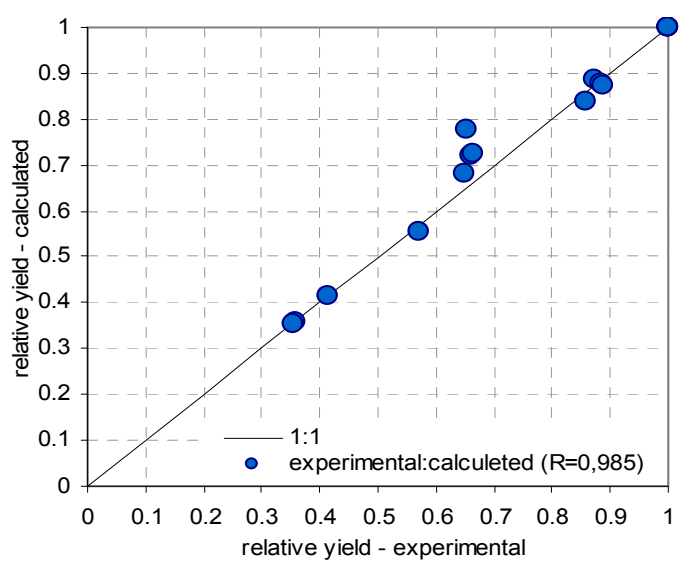

Fig. 6. Relationship "experimental-calculated yield"

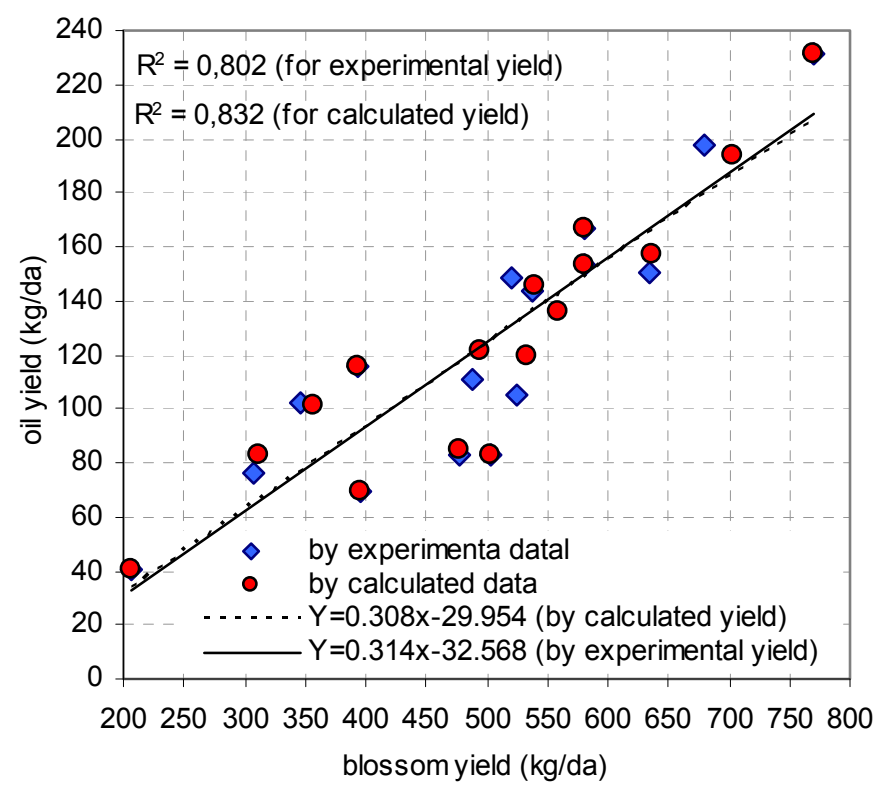

Fig. 7. Relationship between yield of blossom and yield of oil

\section{Conclusions}

The relationship between the yield of blossom and irrigation depth is best expressed by exponential correlation with $n=1.1(1.0 \div 1.2)$ and $R=0.995$. The low exponent is a result of poor positive impact of the reduced irrigation depths on the yield. The calculated yields were slightly higher than the experimental, and the differences do not exceed $4 \%$.

The relationship between the yield of oil and the irrigation depth is subjected to the same exponential correlation with $n=1.1(1.0 \div 1.2)$ and $\mathrm{R}=0.985$. Variation in the calculated yield to the experimental one is from -5.4 to $+13.1 \%$.
There is a linear relationship between the yield of blossom and yield of oil, expressed by the equation: $Y=0.314 x-32.568$ with $R 2=0.802$. Using data of blossom yield can to estimate by this equation yield of oil in advance.

\section{References}

1. Garside, A.L., Lawn, R.J. \& Byth D.E. (1992). Irrigation management of soybean (Glycine max L. Merrill) in a semi arid tropical environment. I. Effect of irrigation frequency on growth development and yield. Australian Journal of Agricultural research, 43 (5), 1003 $-1017$. 
2. Petrova, V. (2010). Evaluation of the Meliorative effects on Water and Thermal Regimes of Crops of Soybean and Wheat. Dissertation, Sofia.

3. Varlev, I. (1983). Optimize the uniformity of irrigation. Agricultural Academy. Sofia.

4. Varlev,I. \& Popova, Z. (1999). Waterevapotranspiration-yield. IHM - Sofia.

5. Varlev, I., (1983). Potential efficiency and risk in maize growing in Bulgaria. Agricultural Academy. Sofia.

6. Diez, R.T., Rojas, P.H. \& Agudelo, D.O. (1998). Funciones agua produccion y eficiencia del uso agua de genotipes de soya, Acta Agronomica, Universidat Nacional de Columbia, 48 (3-4), 28 - 36.

7. Senchukov, G.A. (1986). Effect of irrigation rate on the yield of major crops in the conditions of the Rostov region. Rational use of irrigated crops and programming, 31 - 38 .

8. Nekov, N., Matev, Al. \& Ovcharova, A. (2014). "Additional yield - irrigation depth" relationship for white bearing rose (Rosa Alba L.). Ovidius University Annals - Constantza, Romania, Year XVI - Issue 16, 91 - 104. 9. Davidov, D. (1982). On the "Yield-Water" relationship. Irrigation and Land Reclamation, 7, 18 20 (BG).

10. Davidov, D. \& Gajdarova, St. (1994). Computer Programme for Calculating Crop Yields with and without Irrigation for a Series for Past Years. 17th European Regional Conference on Irrigation and Drainage ICIDCIID, Varna, Bulgaria, 1, 255-260. 